\title{
Demand or productivity: what determines firm growth?
}

\author{
Andrea Pozzi* \\ and \\ Fabiano Schivardi**
}

We disentangle the contribution of unobserved heterogeneity in demand and productivity to firm growth using Italian data containing unique information on firm-level prices. Demand and total factor productivity (TFP) shocks are equally important in shaping firm growth. However, the pass-through of shocks to growth is highly incomplete, more so for productivity shocks. We argue that incompleteness and asymmetry of the pass-through can be explained by frictions that, unlike those studied by the literature on factor misallocation, have differential effects according to the nature of the shock. We propose hurdles to firms' ability to reorganize as an example of these types of frictions.

\section{Introduction}

Modern theories of industry dynamics assume that firms are heterogeneous along a single unobserved dimension, productivity, which determines the firm's performance and growth (Jovanovic, 1982; Hopenhayn, 1992). The empirical literature on the topic has followed this view, tracing back firms' growth to the evolution of productivity (see Syverson, 2011, for a comprehensive survey). However, several other dimensions of heterogeneity may matter. In particular, the assumption that all firms look alike to consumers fails to capture an important ingredient of firm performance. Differences in the effectiveness in marketing, in developing relationships with

\footnotetext{
*Einaudi Institute for Economics and Finance and CEPR; andrea.pozzi@eief.it.

** Università Bocconi, IGIER, Einaudi Institute for Economics and Finance and CEPR; fabiano.schivardi@unibocconi.it. We have benefited from comments by Fernando Alvarez, Jorge Balat, Fabio Canova, Greg Crawford, Jan De Loecker, Alon Eizenberg, Paul Grieco, Nezih Guner, Bob Hall, John Haltiwanger, Hugo Hopenhayn, Rosa Matzkin, Ariel Pakes, Ed Vytlacil, the Editor, and two anonymous referees. We are also grateful to participants at the following seminars, workshops, and conferences: Cagliari, EIEF, EUI, IFN, Oxford, Pompeu Fabra, Scuola Superiore Sant'Anna, Stockholm School of Economics, Mannheim, LUISS, Central European University, Collegio Carlo Alberto, Universitat Autònoma de Barcelona, Università Bocconi, Pennsylvania State University, Wharton School of Business, the Workshop on the productivity of the Italian system (Trento, 2011), EIEF-UNIBO Workshop on Industrial Organization (Bologna, 2011), the $2^{\text {nd }}$ EIEF workshop on structural approaches to productivity and industry dynamics (Rome, 2012), the $11^{\text {th }}$ CAED Conference (Nuremberg, 2012), the CEPR/JIE conference 2012 (Protaras), the SED Annual Meeting 2012 (Limassol), EARIE 2012 (Rome), and IIOC 2014 (Chicago).
} 
customers, in maintaining brand image, and in generating word-of-mouth are only some sources of heterogeneity across firms on the demand side.

The relevance of distinguishing between these two sources of heterogeneity goes beyond the well-known measurement issues (Klette and Griliches, 1996). It also provides insights on the determinants of firm entry, survival, and growth. For example, Foster, Haltiwanger, and Syverson (2008) show that, contrary to a large body of previous evidence, entrants are as productive as incumbents once heterogeneity in demand is properly accounted for. The data requirements to pursue this line of investigation are, however, quite stringent. To separately identify shocks to demand and productivity, one needs to observe firm-level prices, rarely available in the data sets used in the literature. The body of work analyzing idiosyncratic demand and productivity simultaneously is, therefore, still scant.

In this article, we use a data set with survey information on firm-level prices to study how demand and productivity contribute to firm growth. We first disentangle demand and productivity shocks and then analyze the transmission mechanism of these shocks to firm growth. We reach two main conclusions: (i) firms only partially react to shocks and (ii) the lack of responsiveness is more severe after productivity than after demand shocks. We show that the source of such underresponse can be related to the existence of adjustment frictions. This calls for the introduction of a class of frictions that not only constrain response to shocks, as documented by a large literature, but also whose relevance depends on the nature of the shock. We propose one such friction and show that, under assumptions, our findings can be rationalized assuming that firms are heterogeneous in their ability to undertake restructuring, a dimension whose relevance is stressed by the growing literature on managerial practices (Bloom, Sadun, and Van Reenen, 2010).

We start our analysis by setting up a standard model of monopolistic competition on the demand side and Cobb-Douglas technology on the production side, each with its own stochastic shifter. The model is estimated using data on Italian manufacturing firms in the Textile and Leather, Metals, and Machinery sectors, for which the monopolistic competition assumption is likely to be a good representation of market structure. We estimate idiosyncratic demand shocks as the residual of the demand function and circumvent the usual simultaneity problem in demand estimation (Trajtenberg, 1989; Berry, 1994) using a direct assessment of the elasticity of demand provided by the managers in the survey. Productivity shocks are then identified as residuals of the production function equation, with output deflated with firm-level prices. To address the endogeneity of inputs choice, we adapt the Olley and Pakes (1996) procedure to accommodate for nonscalar unobserved heterogeneity.

Next, we use the model and the parameter estimates (but not our estimates of the shocks) to compute a quantitative prediction of firms' response to TFP and demand changes. The comparison between these magnitudes and those obtained by regressing directly measures of output and inputs growth on the estimated shocks in a reduced-form setting shows that the pass-through of shocks to firm growth is incomplete. Furthermore, the degree of under-response is larger for TFP shocks than for demand ones. For example, the elasticity derived from the model implies that a TFP shock equal to one standard deviation of TFP growth would increase output by $29 \%$, whereas using the elasticity estimated in the reduced-form regressions entails only an $11 \%$ effect. In the case of demand, the gap between model predictions and measured effects is much smaller: $18 \%$ versus $12 \%$. This is a novel result: asymmetry in the response can only be detected when considering multiple sources of unobserved heterogeneity, which is the distinctive characteristic of this study.

We analyze several possible explanations for this finding, including attenuation due to error in measurement of the shocks and differences in their persistence. As none of them can completely account for our results, we explore the possibility that the incomplete pass-through of shocks to growth is due to the presence of adjustment frictions. This calls for introducing a class of frictions that hamper response to TFP shocks without necessarily impeding the transmission of demand ones. We provide one example of such frictions by looking at firms' ability to reshape their organization. Under the assumption that the response to TFP shocks require more business process 
reorganization (change in the skill mix of the employees, use of different types of capital inputs, etc.) than that to demand ones, we should observe that the asymmetry in the response between the two shocks is explained by the degree of reorganization ability of the firm. Using several proxies for firms' ability to reorganize and restructure, such as the managers' self-assessment on the organizational flexibility of the firm and measures of managerial and workforce skills that the literature has indicated as complementary to restructuring (Caroli and Van Reenen, 2001; Bresnahan, Brynjolfsson, and Hitt, 2002; Bloom, Sadun, and Van Reenen, 2012), we present evidence that lines up with this prediction.

Our results tie two burgeoning streams of literature. We confirm the presence of hurdles to the efficient allocation of factors across firms as highlighted by a series of contributions documenting their role in generating misallocation of resources (Hsieh and Klenow, 2009; Bartelsman, Haltiwanger, and Scarpetta, 2013; Asker, Collard-Wexler, and De Loecker, 2014; Midrigan and $\mathrm{Xu}, 2014)$. However, the large asymmetry we find in the level of frictions in the transmission of demand and TFP shocks suggests that such barriers cannot be due only to institutional factors like labor market rigidities (Hopenhayn and Rogerson, 1993; Restuccia and Rogerson, 2008) or bribery and political favoritism (Hsieh and Klenow, 2009), as this literature routinely assumes. Such frictions would, in fact, constrain adjustment independently from the nature of the shock. To explain our findings, we rely on insights from scholars emphasizing the role of managerial ability and corporate practices in the exploitation of technology shocks (Bloom, Sadun, and Van Reenen, 2012; Dranove et al., 2014). Our results show that managerial practices are important for not only within-firm productivity growth, but also to enhance the process of efficient factors allocation across firms.

This study relates to a vast literature interested in understanding the determinants of firm growth (Evans, 1987a, 1987b; Dunne, Roberts and Samuelson, 1988, 1989). We extend it by considering multiple sources of unobserved heterogeneity. The importance of disentangling demand and productivity heterogeneity has been stressed by a recent literature. Using data on homogeneous products, Foster, Haltiwanger, and Syverson (2008) were the first to separately identify demand and productivity shocks. They show that failing to disentangle demand and TFP shocks leads to an underestimation of new entrants' contribution to productivity growth. Foster, Haltiwanger, and Syverson (2016) study the process of accumulation of idiosyncratic demand, finding that demand shock builds up slowly and that it depends on past firm sales. Our results complement theirs: though it takes time to build idiosyncratic demand, we show that reacting to its fluctuations is easier than reacting to changes in productivity. Carlsson, Messina, and Skans (2014) apply Structural Vector Autoregression (SVAR) techniques to a panel of Swedish firms to recover permanent innovations to technology and demand and study their effects on firm employment. The methodological and data differences notwithstanding, they also conclude that employment responds to demand shocks, whereas productivity shocks have a very limited effect (if any).

Our methodological approach to separately identifying productivity and idiosyncratic demand components takes advantage of the recent availability of data sets containing direct information on firms' prices (Fan et al., 2012; De Loecker et al., 2016). This strategy allows to expand the set of industries considered beyond those selling homogeneous goods, on which Foster, Haltiwanger, and Syverson (2008) were forced to focus. It is also less reliant on functional form assumptions than studies that isolate physical productivity from confounding demand factors without the benefit of data on firms' prices (De Loecker, 2011).

The rest of the article is organized as follows. Section 2 presents a standard model of a monopolistic competitive firm characterized by demand and productivity shifters. Section 3 introduces the data, and Section 4 presents the estimation approach. Section 5 discusses the effects of the shocks on firm growth and uncovers the incomplete and asymmetric response of growth measures to demand and TFP shocks. Section 6 presents evidence that analyzes the implications of our findings for misallocation and proposes hurdles to reorganization as an example of a friction that generates it. Section 7 concludes. 


\section{The model}

Our theoretical framework relies on a model of monopolistic competition where firms choose inputs to produce output, subject to a CES demand and a Cobb-Douglas production function as in Melitz (2000). The purpose of this setup is twofold. On the one hand, it formalizes the assumptions needed for consistently estimating the parameters of the production and the demand functions. On the other hand, the quantitative predictions based on the structural estimates provide a benchmark to evaluate the results of the growth regressions we will perform in the second part of the study.

Firm $i$ faces a constant elasticity of demand function:

$$
Q_{i t}=P_{i t}^{-\sigma} \Xi_{i t}
$$

where $\sigma>1$ is the elasticity of demand and $\Xi_{i t}$ is a demand shifter, observed by the firm (but not by the econometrician) when choosing output. Other time-specific factors, constant across firms, can be ignored without loss of generality as they will be captured by time dummies in the empirical specification.

The market appeal component $\left(\Xi_{i t}\right)$ picks up heterogeneity in firms' demand driven by differences in the perceived quality of the product, controlling for its physical attributes. It relates to similar concepts introduced by Foster, Haltiwanger, and Syverson (2016) and Gourio and Rudanko (2014), who link it to the stock of consumers who have tried the product in the past (the "customer base"). Other instances of demand shocks consistent with our setting are spreading of good word-of-mouth, improvements in the brand image, and the perception or the visibility of the products, for example, as a result of advertising.

The firm enters the period with a given level of capital stock $\bar{K}_{i t}$, accumulated through investment up to period $t-1$ :

$$
\bar{K}_{i t}=(1-\delta) \bar{K}_{i t-1}+I_{i t-1},
$$

where $\delta$ is the depreciation rate. Although the firm cannot modify the capital stock in place for the current period, it decides the degree of capital utilization $\mathrm{U}_{i t}$. The effective capital used for production is then:

$$
K_{i t}=\mathrm{U}_{i t} \bar{K}_{i t}, \quad 0 \leq \mathrm{U}_{i t} \leq 1 .
$$

We assume that using capital is costly, ${ }^{1}$ so that it may be optimal to use less than the whole installed capacity. For simplicity, we assume that capital depreciation is independent from usage. ${ }^{2}$ The firm produces output combining utilized capital, intermediate inputs, and labor with a Cobb-Douglas production function

$$
Q_{i t}=\Omega_{i t} K_{i t}^{\alpha} L_{i t}^{\beta} M_{i t}^{\gamma},
$$

where $\Omega_{i t}$ is firm TFP. Labor $(L)$ and intermediates $(M)$ can be chosen freely and have no dynamic implications, whereas capital input can be varied through the degree of utilization, up to full utilization. Given $\bar{K}_{i t}$ and after observing $\Omega_{i t}, \Xi_{i t}$, the firm chooses inputs to maximize profits:

$$
\max _{\left\{K_{i t}, L_{i t}, M_{i t}\right\}} P_{i t} Q_{i t}-p_{K} K_{i t}-p_{L} L_{i t}-p_{M} M_{i t},
$$

subject to the demand equation (1), the capital constraint (3), and the production function (4), where $p_{K}, p_{L}, p_{M}$ are the costs of utilizing capital, labor, and intermediate input, respectively.

\footnotetext{
${ }^{1}$ For example, if capital must be used in a fixed proportion $1 / a$ with energy, and the price of energy is $p^{e}$, then the cost of using capital is defined as $r=a * p^{e}$, where we use $r$ as the standard notation for the cost of capital usage.

${ }^{2}$ For some types of capital, such as buildings, this seems the most natural assumption. In general, a component of depreciation is clearly linked to time, independently from usage. Moreover, when capital is used, it might be easier to maintain it in an efficient state.
} 
Assume first that the capital constraint is not binding. In this case, equilibrium quantities do not depend on the capital stock in place. Using lowercase letters to denote logs, the optimal quantity, price, and inputs demand functions are:

$$
\begin{aligned}
& q_{i t}^{*}=c_{q}+\frac{\sigma}{\theta} \omega_{i t}+\frac{(\alpha+\beta+\gamma)}{\theta} \xi_{i t} \\
& p_{i t}^{*}=c_{P}-\frac{1}{\theta} \omega_{i t}+\frac{(1-\alpha-\beta-\gamma)}{\theta} \xi_{i t} \\
& x_{i t}^{*}=c_{x}+\frac{(\sigma-1)}{\theta} \omega_{i t}+\frac{1}{\theta} \xi_{i t},
\end{aligned}
$$

where $\theta \equiv \alpha+\beta+\gamma+\sigma(1-\alpha-\beta-\gamma), x=k, l, m$, and $c_{q}, c_{p}, c_{x}$ are constants. Under decreasing returns to scale $(\alpha+\beta+\gamma<1)$, output increases with productivity and demand shocks; whereas price decreases with productivity and increases with market appeal, and inputs demand increases with both. With constant returns to scale, however, $p^{*}$ depends only on costs parameters and not on demand ones.

Note that, though the markup is constant at $\frac{\sigma}{\sigma-1}$, prices differ across firms. In fact, firms' marginal costs differ for two reasons. First, they are characterized by different efficiency levels $\omega_{i t}$, which directly affect marginal costs given output. Second, if the production function displays nonconstant returns to scale, different levels of $\omega$ and $\xi$ entail different level of output, and therefore, of marginal costs.

In terms of the capital constraint, from equation (8), it follows that the firm uses its full capacity, that is, $U_{i t}=1$, if and only if

$$
\bar{k}_{i t} \leq c_{k}+\frac{(\sigma-1)}{\theta} \omega_{i t}+\frac{1}{\theta} \xi_{i t}
$$

Condition (9) states that the capital stock in place is not a binding constraint as long as the productivity and demand shocks are not too large. In fact, as equation (6) shows, output is increasing in both shocks. In Section A.1 of the web Appendix, ${ }^{3}$ we analyze the case where the constraint binds, which occurs for only $2 \%$ of the observations in our sample. We show that a binding capital constraint does not affect the estimation of the demand and production functions. Instead, the relationship between output and input demand and the shocks does depend on whether the capital constraint is binding. Therefore, we will exclude observations where the capital constraint has been met when we proceed to estimate the elasticity of output and input to shocks in Section 5.

The only dynamic choice the firm faces in our setting is investment, through which the firm can increase the stock of capital in place next period. Following Olley and Pakes (1996), we use investment to control for unobserved productivity in the estimation of the production function. In Section A.2 of the web Appendix, we set up the dynamic problem and show that our investment function depends not only on the capital in place $\bar{k}$ and productivity $\omega$, as in the standard case, but also on the firm's market appeal $\xi$, violating the assumption of scalar unobservability. Ackerberg et al. (2007) argue that the Olley and Pakes (1996) procedure can be generalized to this case by including the demand shifter in the control function:

$$
\omega_{i t}=h\left(i_{i t}, \xi_{i t}, \bar{k}_{i t}\right)
$$

We assume that market appeal and TFP follow first-order Markov processes such that $F_{\Omega}\left(\cdot \mid \Omega_{i t-1}^{\prime}\right)$ first-order stochastic dominates $F_{\Omega}\left(\cdot \mid \Omega_{i t-1}\right)$ for $\Omega_{i t-1}^{\prime}>\Omega_{i t-1}$ and $F_{\Xi}\left(\cdot \mid \Xi_{i t-1}^{\prime}\right)$ firstorder stochastic dominates $F_{\Xi}\left(\cdot \mid \Xi_{i t-1}\right)$ for $\Xi_{i t-1}^{\prime}>\Xi_{i t-1}$. High TFP (market appeal) today implies high expected TFP (market appeal) tomorrow. This assumption is important for the invertibility

\footnotetext{
${ }^{3}$ The web Appendix to this article is available on both authors' personal websites.
} 
of the investment function. Intuitively, the policy function is invertible if, given two firms with the same installed capital and demand shock, investment is strictly higher in the firm with the higher productivity shock.

The setup presented assumes that firms produce a single product. Multiproduct firms pose additional challenges for the estimation as our data report average price changes, total output, and input usage at firm level with no disaggregation for single product lines. In Section A.3 of the web Appendix, we extend the theoretical framework to the case of multiproduct firms and show that, under general conditions, demand and productivity shocks can be recovered also under this scenario. In particular, if demand and productivity shocks are identical across products, as typically assumed in empirical work (Foster, Haltiwanger, and Syverson, 2008; De Loecker, 2011), ${ }^{4}$ the distinction between working with product- or firm-level data blurs. Our methodology works even if demand shocks are specific to individual products, as long as there is a unique production function for all products at the firm level. The use of aggregate firm-level data is, however, problematic when there are product-specific productivity shocks. As far as we know, such a case has not yet been addressed in the empirical literature.

\section{Data description}

The data used in this study come from the "Indagine sugli investimenti delle imprese manifatturiere" (Inquiry into investments of manufacturing firms; henceforth, INVIND), a survey collected yearly since 1984 by the Bank of Italy. The survey is a panel representative of Italian manufacturing firms with at least 50 employees $^{5}$; no plant-level information is available. It contains detailed information on revenues, ownership, capital and debt structure, as well as usage of production factors. Additional firm information is drawn from "Centrale dei Bilanci" (Company Accounts Data Service; henceforth, CB), which includes balance sheets data of around 30,000 Italian firms. Firms in INVIND can be matched to their balance sheet data in CB using their tax identification number.

To ensure homogeneity of the final good produced, we group firms into sectors. We use an aggregation of the statistical classification of economic activities in the European Community (NACE) 2002 and focus on three major sectors: Textile and Leather, Metals, and Mechanical and Electronic Machinery. The characteristics of these three sectors are broadly consistent with the structure of monopolistic competition we impose in the model. The average Herfindahl index over the sample period is 0.001 for Textile and Leather, 0.006 for Metals, and 0.004 for the Machinery sector. The average market share of the top four firms in the sample is $5 \%$ for textile, $10.5 \%$ for metals, and $8.4 \%$ for machinery. ${ }^{6}$

We drop observations pre-1988, because early waves of the survey do not contain information on firm-level prices. We also ignore firms not matched with CB ( $25 \%$ of the INVIND respondents), as well as those not surveyed for at least two consecutive years ( $22 \%$ of the residual sample). After applying these refinements, we are left with a pooled sample of 7759 firm-years over the period 1988-2007.

The information on firm prices contained in the INVIND survey is key to our goal of disentangling demand from TFP shocks. Firms are asked to state the "average percentage change in the prices of goods sold." This implies that we will only be able to exploit this information

\footnotetext{
${ }^{4}$ An important exception is De Loecker et al. (2016), who use a unique data set of Indian firms with information on prices and quantities sold at the product level to estimate marginal costs at the product level. They assume that each product has its own production function, but that there is a unique productivity shock common to all products within the firm.

${ }^{5}$ From 2002, the survey was extended to service firms and the employment threshold lowered to 20 . However, these firms are given a shorter questionnaire, which excludes some of the key variables for our analysis. We therefore focus throughout on manufacturing firms with at least 50 employees.

${ }^{6}$ Note that because firms with fewer than 50 employees are excluded from the sample, we are overestimating the concentration detected by the Herfindahl index.
} 
estimating the model in first differences. ${ }^{7}$ Using the average price change is problematic in cases of introduction of new products and dismission of old ones; in those instances, the price change is not defined. We implicitly assume that the share of products introduced or retired by any firm in a given year is small enough not to affect significantly the average growth rate of price. At the same time, using growth rates also delivers some advantages. For example, for multiproduct firms, the average growth in prices is a more meaningful object than the average price level. Leaving aside the introduction of new products, using first differences nets out any fixed unobserved heterogeneity that might distort the estimates. This is important, because the model assumes that market appeal does not pick up quality differences embodied in physical attributes of the product. Exploiting only variation within firms ensures that (i) cross-firm differences in product quality level do not contribute to identification and (ii) the bulk of the variation in $\Delta p$ for a given firm relates to a given set of products with fixed physical attributes. ${ }^{8}$ It is worth noting, however, that first-differencing does not protect us against changes in average quality due to period-to-period shifts in the firm's output across continued products.

Nominal output is obtained from balance sheets data in CB. We deflate its growth rate using firm-level price changes to obtain real output growth. Labor input is measured as hours worked and intermediate inputs come from CB and are deflated with sectoral prices. To measure capital inputs, we exploit questions in INVIND on production capacity ${ }^{9}$ and the degree of capacity utilization. Direct assessment of the change in installed productive capacity $\Delta \bar{k}$ helps us to circumvent issues of measurement error linked to standard measures of capital based on book values or permanent inventory method. Utilized capital is a better measure of capital services in the production function than installed capital. Using installed capital implicitly assumes that the degree of capital utilization is $100 \%$. This is not borne in the data: the average degree of capacity utilization is $81 \%$, with a standard deviation of $13 \%$; the $5^{\text {th }}$ and the $95^{\text {th }}$ percentile are $60 \%$ and $98 \%$, respectively.

Moreover, utilized capital displays additional variation that is useful for identification. Estimating the production function in first differences, we rely exclusively on the within-firm variation in the capital input. This poses a challenge for the estimation of its coefficient, as capital in place typically varies little within-firm. The stickiness of installed capital also implies that even small amounts of measurement error in levels could translate in measurement error accounting for a large fraction of the variation of the capital input in first differences. Luckily, the utilized capital variable displays plenty of within-firm variation: a variance decomposition reveals that within variation represents between $83 \%$ (for the textile sector) and $92 \%$ (for the metals sector) of the between variation. ${ }^{10}$ The within-firm ratio between the minimum and maximum utilized capital confirms that utilization swings significantly within-firm: the upper bound is about $35 \%$ higher than the lower bound, consistently across sectors. Finally, the autocorrelation within-firm in capital utilization is high (.65) but nowhere near a unit root, leaving room for appreciable year-to-year variation.

Table 1 reports descriptive statistics for our key variables both in levels (Panel A) and in growth rates (Panel B). A first look at growth rates shows that quantity sold and output grew on average $1.8 \%$ per year over the sample period, with a standard deviation of 0.18 . Labor input

${ }^{7}$ Firms report \%price change $\equiv \frac{P_{i t}}{P_{i t-1}}-1$. We use this figure to obtain the first difference in the logarithm of price $\Delta p$. We obtain the growth rate of the logged prices using the transformation $\Delta p=\ln (1+\%$ price change $)$. All the variables reported in the survey as percentage changes are transformed in the same way.

${ }^{8}$ To validate the quality of the information in the INVIND survey and in particular that of the price variable in Section B.1 of the web Appendix, we compare a price index built upon INVIND prices with that constructed by the national statistical office (ISTAT). The two series are highly correlated.

${ }^{9}$ This variable corresponds to $\bar{K}_{i t}$ in the notation of Section 2, and is defined as "the maximum output that can be obtained using the plants at full capacity, without changing the organization of the work shifts. "In alternative, we have experimented with permanent inventory measures of the capital stock.

${ }^{10}$ The statistics are calculated taking the ratio of the standard deviation of the deviations from the firm-specific mean (st.dev. $\left.\left(U_{i t}-\overline{U_{i}}\right)\right)$ and the standard deviation across firms of the firm-specific average capital utilization $\left(\right.$ st.dev. $\left.\left(\overline{U_{i}}\right)\right)$. 
TABLE 1 Summary Statistics for Main Variables, by Sector

\begin{tabular}{|c|c|c|c|c|}
\hline & All & Textile and Leather & Metals & Machinery \\
\hline \multicolumn{5}{|c|}{ Panel A: Levels } \\
\hline Revenues & $\begin{array}{c}92,011 \\
(241,680)\end{array}$ & $\begin{array}{c}54,555 \\
(110,161)\end{array}$ & $\begin{array}{c}120,329 \\
(345,491)\end{array}$ & $\begin{array}{c}107,534 \\
(245,949)\end{array}$ \\
\hline Output & $\begin{array}{c}93,374 \\
(242,981)\end{array}$ & $\begin{array}{c}54,876 \\
(110,557)\end{array}$ & $\begin{array}{c}122,603 \\
(346,912)\end{array}$ & $\begin{array}{c}109,255 \\
(247,527)\end{array}$ \\
\hline Workers & $\begin{array}{c}426 \\
(995)\end{array}$ & $\begin{array}{c}314 \\
(562)\end{array}$ & $\begin{array}{c}341 \\
(915)\end{array}$ & $\begin{array}{c}568 \\
(1,275)\end{array}$ \\
\hline \multicolumn{5}{|c|}{ Panel B: Growth Rates } \\
\hline$\Delta$ Output & 0.018 & -0.005 & 0.021 & 0.037 \\
\hline sold & $(0.18)$ & $(0.17)$ & $(0.17)$ & $(0.19)$ \\
\hline$\Delta$ Output & 0.019 & -0.006 & 0.034 & 0.031 \\
\hline produced & $(0.21)$ & $(0.20)$ & $(0.20)$ & $(0.23)$ \\
\hline$\Delta$ Interm. & 0.020 & -0.010 & 0.030 & 0.039 \\
\hline inputs & $(0.32)$ & $(0.30)$ & $(0.31)$ & $(0.34)$ \\
\hline$\Delta$ Hours & -0.005 & -0.018 & 0.003 & 0.001 \\
\hline worked & $(0.14)$ & $(0.14)$ & $(0.13)$ & $(0.14)$ \\
\hline$\Delta$ Utilized & 0.035 & 0.014 & 0.052 & 0.043 \\
\hline capital & $(0.19)$ & $(0.20)$ & $(0.18)$ & $(0.19)$ \\
\hline \multirow{2}{*}{$\Delta$ Prices } & 0.022 & 0.023 & 0.027 & 0.017 \\
\hline & $(0.06)$ & $(0.05)$ & $(0.08)$ & $(0.06)$ \\
\hline Obs. & 7654 & 2686 & 1836 & 3132 \\
\hline
\end{tabular}

Notes: Figures reported are sample averages; standard deviations are in parentheses. Revenues and Output are expressed in thousands of 2007 euros. $\Delta$ Output sold and $\Delta$ Output produced are computed net of growth in firm-level prices.

\section{FIGURE 1}

DISTRIBUTION OF PRICE CHANGES IN 2004, BY SECTOR

(a) Textile and leather

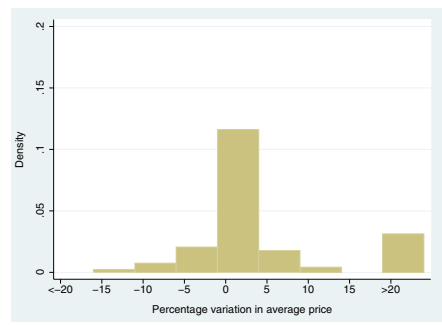

(b) Metals

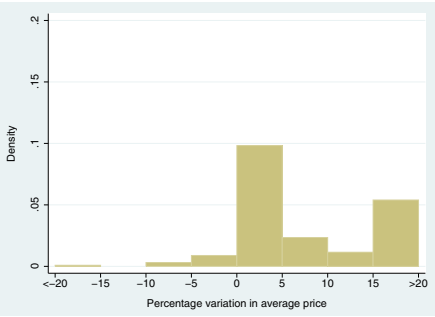

(c) Machinery

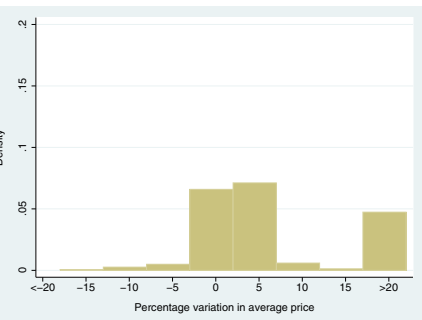

contracted slightly, whereas capital input grew at 3.5\% yearly. The average firm in the sample raises prices by over $2 \%$ per year. Figure 1 shows the distribution of price changes for each of the three sectors in one year of our data. The picture confirms that there is substantial dispersion around the sectoral average and reaffirms the importance of having information on firm-level price adjustments.

\section{Demand and TFP estimation}

Demand estimation. Firms face a CES demand function of the form expressed in equation (1). We estimate a first differences specification of the following form separately for each of the sectors in our sample:

$$
\Delta q_{i t}=\Delta \xi_{i t}-\sigma \Delta p_{i t}
$$


(a) Textile and leather

(b) Metals

(c) Machinery

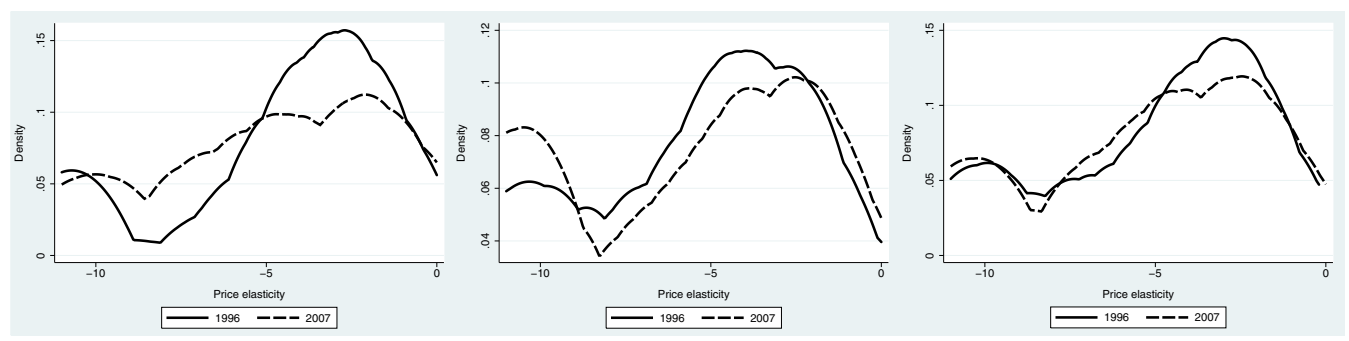

The shock to market appeal, $\Delta \xi_{i t}$, is known to the firm but unobserved to the econometrician. If we obtained consistent estimates of the price elasticity $(\sigma)$, we could exploit the information on price changes to estimate $\Delta \xi_{i t}$ as follows:

$$
\widehat{\Delta \xi_{i t}}=\Delta q_{i t}+\hat{\sigma} \Delta p_{i t} .
$$

Estimation of equation (11) is complicated by the classic simultaneity problem. Positive shocks to market appeal lead producers to raise prices, as shown in equation (7), making $\Delta p$ and $\Delta \xi$ positively correlated. Therefore, plain OLS would understate demand elasticity. In our context, finding valid instruments for price constitutes a challenge. To solve this problem, we exploit a unique piece of information included in our data. In 1996 and in 2007, the interviewed managers were directly asked to report the elasticity of the demand faced by their firm answering the following question:

"Consider the following thought experiment: if your firm increased prices by $10 \%$ today, what would be the percentage variation in its revenues, provided that competitors did not adjust their pricing and all other things being equal?"

As managers are explicitly asked to perform a thought exercise isolating the effect of price changes on demand, the estimates we derive from their answers should not be affected by simultaneity. Therefore, we choose to rely upon answers to this question to estimate a sectorspecific demand elasticity as the average of the elasticities reported by firms belonging to a given sector. Figure 2 reports kernel densities by sector for the distribution of self-reported elasticities in the two waves. They look similar, and a Kolmogorov-Smirnov test does not reject the equality of the distributions. We use elasticities reported by the cross-section of representative firms interviewed in 1996 to estimate $\sigma$ because this wave falls in the middle of our sample period and the response rate (over 80\%) is higher than in 2007.

Table 2 presents estimated demand elasticities separately for each sector. In the first column, we list average sectoral self-reported demand elasticities from the 1996 wave of INVIND. Elasticities range between 4.5 and 5.5; these values are in the order of those found of the literature. For instance, our estimate for textile is similar to that reported by De Loecker (2011), who looks at several segments within the textile sector in Belgium. Hsieh and Klenow (2009) in their calibration exercise use what they refer to as a conservative value of 3 and check the robustness of their results with an alternative value of 5. In Section B.2 of the web Appendix, we comment on additional results reported in Table 2, where we check whether the presence of multiproduct, multiplant, and exporting firms affects our estimates of price elasticity. We also compare the results based on self-reported information with those obtained exploiting Foster, Haltiwanger, and Syverson (2008) IV strategy. The findings are in line with those in Column 1, with the exception of OLS, where, as expected, not accounting for endogeneity leads to substantially lower estimates. 
TABLE 2 Estimates of $\sigma$, By Sector

\begin{tabular}{|c|c|c|c|c|c|c|}
\hline & $\begin{array}{c}(1) \\
\text { All } \\
\text { Firms }\end{array}$ & $\begin{array}{c}(2) \\
\text { Single Product } \\
\text { Firms }\end{array}$ & $\begin{array}{l}\text { (3) } \\
\text { Single Plant } \\
\text { Firms }\end{array}$ & $\begin{array}{c}\text { (4) } \\
\text { NonExporting } \\
\text { Firms }\end{array}$ & $\begin{array}{c}(5) \\
\text { OLS }\end{array}$ & $\begin{array}{l}\text { (6) } \\
\text { IV }\end{array}$ \\
\hline Textile and leather & $\begin{array}{c}4.5 \\
(3.3)\end{array}$ & $\begin{array}{c}4.7 \\
(3.3)\end{array}$ & $\begin{array}{c}4.6 \\
(3.4)\end{array}$ & $\begin{array}{c}8 \\
(3.7)\end{array}$ & $\begin{array}{c}0.27 \\
(0.08)\end{array}$ & $\begin{array}{c}6.1 \\
(0.54)\end{array}$ \\
\hline Metals & $\begin{array}{c}5.5 \\
(3.5)\end{array}$ & $\begin{array}{c}6.4 \\
(3.5)\end{array}$ & $\begin{array}{c}5.3 \\
(3.6)\end{array}$ & $\begin{array}{c}7 \\
(0)\end{array}$ & $\begin{array}{c}0.26 \\
(0.05)\end{array}$ & $\begin{array}{c}4.9 \\
(0.62)\end{array}$ \\
\hline Machinery & $\begin{array}{c}5 \\
(3.2)\end{array}$ & $\begin{array}{c}5.1 \\
(3.1)\end{array}$ & $\begin{array}{c}5.1 \\
(3.2)\end{array}$ & $\begin{array}{l}7.4 \\
(4)\end{array}$ & $\begin{array}{c}0.29 \\
(0.10)\end{array}$ & $\begin{array}{c}5.7 \\
(0.46)\end{array}$ \\
\hline
\end{tabular}

Notes: In the first four columns, we report the average of the self-reported price elasticities and their standard deviations (in parentheses). In the last two columns, we report the coefficient of the price variable in an OLS and IV specification, respectively, and the standard error of the estimate (in parentheses). Single-product firms are defined as those claiming to derive at least $80 \%$ of their revenues from a single product line. Single-plant firms are those reporting that all their employees work in the same macro region. The IV column uses unexpected variation in $\triangle \mathrm{TFP}$ as instrument (see Section B.2 of the web Appendix).

TFP estimation. We directly estimate a quantity (as opposed to revenue) production function in first differences as in the equation below:

$$
\Delta q_{i t}=\alpha \Delta k_{i t}+\beta \Delta l_{i t}+\gamma \Delta m_{i t}+\Delta \omega_{i t}+\Delta \eta_{i t},
$$

where the overall TFP shock is given by the sum of $\omega_{i t}$, the component of TFP inputs react to, and which is the source endogeneity, and $\eta_{i t}$, the component unrelated to inputs choice. We compute the growth rate of real output by subtracting the price change from the nominal output growth. ${ }^{11}$

To account for the endogeneity of inputs, we follow the control function approach introduced by Olley and Pakes (1996). Our setting differs from the standard one along three dimensions. First, we estimate the production function in first differences rather than in levels. Second, firms are characterized by two unobservables, TFP and $\xi$, rather than just one. This requires adjusting the standard procedure to relax the scalar unobservability assumption. Finally, we measure the capital input as utilized capital, so that the capital actually used in production can be adjusted after observing the shocks, rather than being predetermined. We discuss in detail the technical issues raised by these differences in Section B.3 of the web Appendix.

We use as control function a third-degree polynomial in $\Delta \xi_{i t}, \Delta i_{i t}, \Delta \bar{k}_{i t}$, and estimate the production function using the following regression equation (year dummies are included in each specification $)^{12}$ :

$$
\Delta q_{i t}=\alpha \Delta k_{i t}+\beta \Delta l_{i t}+\gamma \Delta m_{i t}+h\left(\Delta \xi_{i t}, \Delta i_{i t}, \Delta \bar{k}_{i t}\right)+\Delta \eta_{i t} .
$$

Once we have estimated the coefficients, we recover the changes in TFP as

$$
\widehat{\Delta T F P}_{i t}=\Delta q_{i t}-\hat{\alpha} \Delta k_{i t}-\hat{\beta} \Delta l_{i t}-\hat{\gamma} \Delta m_{i t} .
$$

Panel A of Table 3 reports sector-by-sector estimates of the coefficients of the production function. We find evidence of decreasing returns to scale for all sectors: the degree of returns to scale $\alpha+\beta+\gamma$, reported in the last row of the panel, is between 0.8 and 0.85 . Klette and Griliches (1996) show that without knowledge of firm prices, not only will estimated productivity be different from effective one but also the coefficients estimated using revenue data will be inconsistent.

${ }^{11}$ We use output instead of value added to avoid overstating productivity dispersion (Gandhi, Navarro, and Rivers, 2013). Because market appeal shocks are computed from quantities, using output to obtain TFP also makes the two shocks more comparable. Output and quantities differ only due to inventories, using a value-added production function would introduce intermediate goods as well.

${ }^{12}$ We use a polynomial in first differences of the control variables. As $\Delta h(x) \neq h(\Delta x)$, we should instead use the contemporaneous and lagged values of the levels which, however, we cannot compute. In Section B.5 of the web Appendix, we show that this shortcut does not seem to significantly affect our results. 
TABLE 3 Production Function Estimation

\begin{tabular}{|c|c|c|c|}
\hline & $\begin{array}{c}\text { (1) } \\
\text { Txt. + Leather }\end{array}$ & $\begin{array}{c}(2) \\
\text { Metals }\end{array}$ & $\begin{array}{c}(3) \\
\text { Machinery }\end{array}$ \\
\hline \multicolumn{4}{|c|}{ Panel A: Output Deflated with Firm Prices } \\
\hline$\Delta k$ & $\begin{array}{c}0.14^{* * *} \\
(0.027)\end{array}$ & $\begin{array}{c}0.08^{* * *} \\
(0.028)\end{array}$ & $\begin{array}{c}0.11^{* * *} \\
(0.023)\end{array}$ \\
\hline$\Delta l$ & $\begin{array}{c}0.17^{* * *} \\
(0.025)\end{array}$ & $\begin{array}{c}0.24^{* * *} \\
(0.031)\end{array}$ & $\begin{array}{c}0.17^{* * *} \\
(0.029)\end{array}$ \\
\hline$\Delta m$ & $\begin{array}{c}0.49^{* * *} \\
(0.023)\end{array}$ & $\begin{array}{c}0.52^{* * *} \\
(0.023)\end{array}$ & $\begin{array}{c}0.52^{* * *} \\
(0.019)\end{array}$ \\
\hline $\begin{array}{l}\alpha+\beta+\gamma \\
\text { Obs. } \\
R^{2}\end{array}$ & $\begin{array}{l}0.8 \\
1800 \\
0.67\end{array}$ & $\begin{array}{l}0.85 \\
1354 \\
0.65\end{array}$ & $\begin{array}{l}0.8 \\
2071 \\
0.72\end{array}$ \\
\hline \multicolumn{4}{|c|}{ Panel B: Output Deflated with Sectoral Prices } \\
\hline$\Delta k$ & $\begin{array}{l}0.11^{* * *} \\
(0.023)\end{array}$ & $\begin{array}{c}0.07^{* * *} \\
(0.024)\end{array}$ & $\begin{array}{c}0.08^{* * *} \\
(0.018)\end{array}$ \\
\hline$\Delta l$ & $\begin{array}{l}0.13^{* * *} \\
(0.022)\end{array}$ & $\begin{array}{c}0.17^{* * *} \\
(0.027)\end{array}$ & $\begin{array}{c}0.15^{* * *} \\
(0.023)\end{array}$ \\
\hline$\Delta m$ & $\begin{array}{l}0.43^{* * *} \\
(0.020)\end{array}$ & $\begin{array}{c}0.47^{* * *} \\
(0.021)\end{array}$ & $\begin{array}{c}0.50^{* * *} \\
(0.017)\end{array}$ \\
\hline$\tilde{\alpha}+\tilde{\beta}+\tilde{\gamma}$ & 0.67 & 0.71 & 0.73 \\
\hline$\frac{\sigma(\tilde{\alpha}+\tilde{\beta}+\tilde{\gamma})}{\sigma-1}$ & 0.86 & 0.86 & 0.91 \\
\hline Obs. & 1806 & 1356 & 2076 \\
\hline$R^{2}$ & 0.77 & 0.76 & 0.79 \\
\hline
\end{tabular}

Notes: The dependent variable is the growth rate of output, deflated with firm-level prices. $\Delta k$ is the log difference of the stock of capital used in production, taking capital utilization into account, $\Delta l$ is the log difference of the number of hours worked, and $\Delta m$ is the log difference of intermediates. All regressions include the control function and year dummies. Robust standard errors are reported in parentheses. Significance levels: *: $10 \%, * *: 5 \%, * * *: 1 \%$.

In fact, using (1) and (4) and taking logs, it is straightforward to show that a revenue production function can be expressed as:

$$
q_{i t}+p_{i t}=\frac{\sigma-1}{\sigma} \alpha k_{i t}+\frac{\sigma-1}{\sigma} \beta l_{i t}+\frac{\sigma-1}{\sigma} \gamma m_{i t}+\frac{\sigma-1}{\sigma} \omega_{i t}+\frac{1}{\sigma} \xi_{i t} .
$$

Even if we accounted for the endogeneity of inputs, the coefficients of a revenue function still underestimate the true degree of returns to scale. As shown in Melitz (2000), the size of the bias is $\frac{\sigma-1}{\sigma}$. Intuitively, when a firm expands its output, it must decrease the price to move down the demand curve, so that the increase of physical output translates less than proportionally in the increase in revenues.

In Panel B, we run the estimation procedure using output deflated with sectoral prices rather than with firm-level prices. For all sectors, the real output-based estimates are larger than the revenue-based estimates, as predicted by Klette and Griliches (1996). In the last row of the table, we compute the returns to scale obtained using the Melitz (2000) correction, where $\sigma$ is the sectoral self-reported elasticities reported in Table 2. Applying the correction to the estimates based on sectoral deflators brings them close to those obtained using output deflated with firmlevel prices, with the exception of the machinery sector, where the correction delivers a higher elasticity.

First differencing may exacerbate measurement error in the independent variables, introducing bias in the coefficients. Although we cannot run the regressions in levels, we rule out this possibility by repeating the exercise, increasing the length of the lag on which the production function is estimated. As the lag increases, the size of the measurement error should decline, because we consider lower frequency movements in inputs and output. Estimates of the production 
TABLE 4 Descriptive Statistics: $\Delta$ TFP and $\Delta \xi$

\begin{tabular}{|c|c|c|c|c|c|c|c|c|}
\hline & \multirow[b]{2}{*}{$\mathrm{N}$} & \multirow[b]{2}{*}{ Mean } & \multirow[b]{2}{*}{ Standard Deviation } & \multicolumn{5}{|c|}{ Percentiles } \\
\hline & & & & 5 th & 25 th & 50 th & 75 th & 95th \\
\hline \multicolumn{9}{|c|}{ Panel A: $\triangle \mathrm{TFP}$} \\
\hline$\triangle$ TFP Olley and Pakes & 7654 & 0.005 & 0.13 & -0.15 & -0.04 & 0.007 & 0.05 & 0.16 \\
\hline$\Delta^{3} \mathrm{TFP}$ & 7654 & 0.003 & 0.14 & -0.16 & -0.04 & 0.003 & 0.05 & 0.16 \\
\hline \multicolumn{9}{|c|}{ Panel B: $\Delta \xi$} \\
\hline Sectoral avg. & 7654 & 0.010 & 0.32 & -0.46 & -0.12 & 0.01 & 0.15 & 0.46 \\
\hline Class avg. & 6490 & 0.005 & 0.34 & -0.48 & -0.12 & 0.01 & 0.14 & 0.45 \\
\hline Individual reported & 720 & 0.004 & 0.42 & -0.56 & -0.11 & 0.03 & 0.16 & 0.53 \\
\hline \multicolumn{9}{|c|}{ Panel C: Serial Correlation in TFP and $\xi$} \\
\hline & \multicolumn{2}{|c|}{$\begin{array}{c}\rho \\
\text { (standard error) }\end{array}$} & & \multicolumn{2}{|l|}{$\begin{array}{c}\text { F-Stat } \\
(\text { Prob }>F)\end{array}$} & & \multicolumn{2}{|c|}{$\begin{array}{c}\text { Overid Test } \\
\quad(p \text {-val })\end{array}$} \\
\hline$\triangle \mathrm{TFP}$ & \multicolumn{2}{|r|}{$\begin{array}{c}0.978^{*} \\
(0.573)\end{array}$} & & \multicolumn{2}{|l|}{$\begin{array}{c}3.414 \\
(0.033)\end{array}$} & & \multicolumn{2}{|c|}{$\begin{array}{r}0.467 \\
(0.49)\end{array}$} \\
\hline$\Delta \xi$ & \multicolumn{2}{|r|}{$0.195^{*}$} & & \multicolumn{2}{|l|}{$(0.000)$} & & \multicolumn{2}{|c|}{$(0.17)$} \\
\hline
\end{tabular}

Notes: Olley and Pakes refers to estimates of TFP recovered using Olley and Pakes (1996); $\Delta^{3}$ TFP reports estimates obtained through the same methodology but using three-year differences in the estimation of the production function (rather than first differences). Sectoral and class rows refer to estimates of $\Delta \xi$ obtained using self-reported elasticities averaging firm responses at the sector and class level, respectively. The row individual reports estimates of $\Delta \xi$ which rely only on the firms that replied directly to the question on price elasticity in the 1996 wave of INVIND. Panel C reports the correlation coefficient obtained regressing $\Delta \mathrm{TFP}_{t}$ on $\Delta \mathrm{TFP}_{t-1}$, instrumenting the latter with $\Delta \mathrm{TFP}_{t-2}$ and $\Delta \xi_{t-2}$, and similarly for $\Delta \xi$. Each line represents a separate regression. Robust standard error in parentheses. Significance levels :*: $5 \% * *: 1 \%$. Overid test is Sargans $\chi^{2}$ test of exogeneity of the instruments.

function using differences over a three-year period are reported in the web Appendix (Table A-5). The degree of returns to scale increases but the resulting TFP estimates are similar to the baseline ones, with a correlation of 0.97 .

Descriptive statistics on $\Delta$ TFP and $\Delta \xi$. Panel A of Table 4 shows descriptive statistics for estimated shocks to productivity ( $\triangle \mathrm{TFP}$ ) pooled across sectors. The average growth rate is below $1 \%$, consistently with the well-documented low productivity growth that has characterized the Italian economy since the early 1990s (Brandolini and Cipollone, 2001). There is also substantial dispersion in TFP growth (the standard deviation is 0.13 ). The second row reports the distribution of TFP computed using the estimates of the production function based on three-year differences. The two distributions are virtually identical.

Panel B reports analogous information for $\Delta \xi$. The row labeled "Sector averages" displays estimates for $\Delta \xi$ based on the self-reported elasticities contained in the 1996 wave of the INVIND survey, averaged at the sectoral level. We also report estimates of $\Delta \xi$ based on elasticities averaged at the NACE class level, a much finer definition of the area of activity. ${ }^{13}$ The estimates labeled "individual reported" are obtained using the individually reported estimates, rather than sectoral averages. In that case, we can use only the firms that directly answered the question in 1996. There are some differences in the means of the distributions of the $\Delta \xi$ estimated using different levels of aggregation. However, these discrepancies are entirely due to outliers. If we compare the distributions, the estimates lead to nearly identical results.

${ }^{13}$ As an example, production of iron and noniron metals belong to different classes of activities within the sector Metals. Similarly, the classes within the Machine sector distinguish between firms producing components for computers and those making them for telecommunication devices. 
TABLE 5 Quantity Sold and Output Growth

\begin{tabular}{|c|c|c|c|c|c|}
\hline & \multicolumn{2}{|c|}{ Output Sold } & \multirow{2}{*}{$\begin{array}{c}\text { Price } \\
(3)\end{array}$} & \multicolumn{2}{|c|}{ Output Produced } \\
\hline & $\begin{array}{c}\text { (1) } \\
\text { Revenues }\end{array}$ & $\begin{array}{c}\text { (2) } \\
\text { Quantity }\end{array}$ & & $\begin{array}{c}(4) \\
\text { Value }\end{array}$ & $\begin{array}{c}\text { (5) } \\
\text { Quantity }\end{array}$ \\
\hline$\triangle \mathrm{TFP}$ & $\begin{array}{c}0.66^{* * *} \\
(0.019)\end{array}$ & $\begin{array}{c}0.82^{* * *} \\
(0.024)\end{array}$ & $\begin{array}{c}-0.17^{* * *} \\
(0.005)\end{array}$ & $\begin{array}{c}0.85^{* * *} \\
(0.024)\end{array}$ & $\begin{array}{c}1.03^{* * *} \\
(0.023)\end{array}$ \\
\hline$\Delta \xi$ & $\begin{array}{c}0.44^{* * *} \\
(0.007)\end{array}$ & $\begin{array}{c}0.29^{* * *} \\
(0.008)\end{array}$ & $\begin{array}{c}.13^{* * *} \\
(0.002)\end{array}$ & $\begin{array}{c}0.37^{* * *} \\
(0.006)\end{array}$ & $\begin{array}{c}0.24^{* * *} \\
(0.007)\end{array}$ \\
\hline Observations & 6566 & 6566 & 6555 & 6587 & 6543 \\
\hline$R^{2}$ & 0.70 & 0.50 & 0.76 & 0.61 & 0.53 \\
\hline
\end{tabular}

Notes: All dependent variables and the demand and TFP shocks are in delta logs. $\triangle$ TFP is calculated using Olley and Pakes (1996) control function approach. $\Delta \xi$ is computed using self-reported sectoral price elasticities from the INVIND survey 1996. The columns labeled "Quantity" use output and revenues deflated using individual firm prices, rather than a sectoral deflator. All specifications include region and industry-year fixed effects. Dependent and independent variables are trimmed to drop outliers above the 99th or below the 1st percentile. Standard errors are calculated from 500 bootstrap simulations. Significance levels: *: $10 \%, * *: 5 \%, * * *: 1 \%$.

The correlation between $\Delta \xi$ and $\triangle T F P$ is nearly zero, validating the assumption of independence made by Foster, Haltiwanger, and Syverson (2008) when using TFP as an instrument for $\xi$ in the pricing equation. Estimating the degree of serial correlation under the assumption that both $\xi$ and TFP are AR(1) processes is more complicated, as first differencing invalidates OLS regressions of each variable on its lagged value. However, it is easy to show that $\Delta \xi_{t-2}$ and $\triangle T F P_{t-2}$ are valid instruments, as they are correlated with lags at $t-1$ but uncorrelated with the residual. We report the results of IV regressions for $\Delta \xi$ and $\triangle T F P$ in Panel $\mathrm{C}$ of Table 1 . We find a degree of serial correlation close to 1 for TFP and of 0.2 for $\xi$; the statistical significance is around $10 \%$ in both cases. The first number is consistent with Foster, Haltiwanger, and Syverson (2008), whereas the latter is substantially lower; both should be taken with caution. In fact, the estimates are sensitive to the choice of instruments and to the treatment of outliers, and the first-stage regression signals a potential weak instrument problem for TFP (F-statistic of 3.41). Moreover, the estimates are not very precise and we should not read too much into our inability to reject the null of the same persistence for the two processes.

\section{Shocks and firm growth}

Armed with our estimates of shocks to TFP and market appeal, we are now ready to quantify their importance in driving firm growth. After measuring the responsiveness of growth to each of the two shocks, we will use the model developed in Section 2 as a benchmark against which to assess it.

Measurement. Under our maintained assumption that the process generating shocks to TFP and market appeal is exogenous, we can assess the elasticity of growth measures to these shocks by estimating regressions of the following form:

$$
\Delta y_{i t}=a_{0}+a_{1} \Delta T F P_{i t}+a_{2} \Delta \xi_{i t}+a_{X} X_{i t}+e_{i t},
$$

where $\Delta y_{i t}$ is the growth rate of some variable of interest (revenues and output, prices, inputs), $\Delta \mathrm{TFP}$ and $\Delta \xi$ are the estimated shocks, and $X_{i t}$ are additional controls.

Table 5 reports the results of a set of such regressions for output and price. We report results from pooled cross-sectoral estimates, where we account flexibly for cross-sectoral heterogeneity through a full set of time-sector dummies. We also include location dummies for five macro-regions of Italy. Sectoral estimates, reported in the web Appendix, are in line with the 
pooled ones. ${ }^{14}$ We account for the fact that $\Delta$ TFP and $\Delta \xi$ are generated regressors by bootstrapping the standard errors.

Column (1) shows that shocks to demand and to TFP have a positive impact on nominal revenues growth. The elasticity of sales to TFP shocks is larger than that to market appeal $(0.66$ versus 0.44 ). Once we factor in dispersion of the shocks, however, we find that one standard deviation change in $\Delta$ TFP would increase sales by $11 \%$, whereas a similar change in $\Delta \xi$ would have an impact of $12 \%$. Demand shocks, therefore, have a stronger effect than productivity ones in determining the evolution of market shares. Once we move from revenues to quantity sold (Column 2), however, the elasticity to TFP grows and that to demand shrinks: a standard deviation increase in TFP increases real sales by $10 \%$ against $9 \%$ for market appeal. This is not surprising, because we are removing the price effect that tends to inflate the response of revenue after demand shocks and reduce that following productivity gains. In fact, a firm experiencing a positive demand shock should not only increase the quantity sold but also the price, whereas the opposite should occur for TFP shocks. Accordingly, in Column (3), we show that positive shocks to TFP lead to price cuts and improvements in demand appeal trigger price raises. The positive effect of demand shocks on prices is also consistent with our findings of decreasing returns to scale. In fact, in a constant returns-to-scale scenario, variations in market appeal should not affect the price.

The results presented in columns (1) and (2) use revenues and quantity sold as a proxy for output. Whereas these are the variables we want to consider when thinking about demand and, therefore, the market appeal component, it could affect measurement when we turn to productivity. In fact, quantity sold and quantity produced do not have to coincide, due to inventories. As we have information on quantity produced, in the last two columns of Table 5 we repeat the exercise, using it as the dependent variable and check whether results are robust. We find that the elasticity of TFP shocks increases by about 0.2 relative to specifications using revenues and quantity sold, whereas the coefficients of demand shocks decrease slightly.

The figures presented above refer to the overall effect of productivity and market appeal on output. For TFP, this is the sum of a direct and an indirect effect. Positive changes in TFP directly increase the quantity produced but should also have an indirect impact as they affect demand for factors of production $l, k, m$. For $\xi$, however, the effect comes entirely through the indirect channel, as demand shocks have no direct contribution to the quantity produced. Total differentiation of equation (13) delivers a decomposition of the overall effect of the two shocks on output:

$$
\begin{aligned}
& \frac{d \Delta q_{i t}}{d \Delta \omega_{i t}}=\underbrace{1}_{\text {direct effect }}+\underbrace{\alpha \frac{\partial \Delta k_{i t}}{\partial \Delta \omega_{i t}}+\beta \frac{\partial \Delta l_{i t}}{\partial \Delta \omega_{i t}}+\gamma \frac{\partial \Delta m_{i t}}{\partial \Delta \omega_{i t}}}_{\text {indirect effect }} \\
& \frac{d \Delta q_{i t}}{d \Delta \xi_{i t}}=\underbrace{\alpha \frac{\partial \Delta k_{i t}}{\partial \Delta \xi_{i t}}+\beta \frac{\partial \Delta l_{i t}}{\partial \Delta \xi_{i t}}+\gamma \frac{\partial \Delta m_{i t}}{\partial \Delta \xi_{i t}}}_{\text {indirect effect }},
\end{aligned}
$$

where, according to equation (8), $\frac{\partial \Delta x_{i t}}{\partial \Delta \omega_{i t}}=\frac{\sigma-1}{\theta}$ and $\frac{\partial \Delta x_{i t}}{\partial \Delta \xi_{i t}}=\frac{1}{\theta}$, for $x=\{k, l, m\}$. Given that we found a unit elasticity of output to TFP shocks in Table 5 , we expect an indirect effect of inputs demand close to zero. Panel A of Table 6 reports the growth of inputs on demand and TFP shocks. Inputs appear more responsive to demand than productivity shocks and, with the exception of intermediate goods, the elasticity of inputs to TFP is negligible in magnitude.

We assumed that variable inputs (hours worked, utilized capital, intermediates) can be adjusted in the short run, thus representing an intensive margin. However, there is a limit to the

\footnotetext{
${ }^{14}$ We have also performed firm fixed effects regressions to control for unobserved heterogeneity within sector, finding no significant variation in the results. This seems to indicate that first differences are already purging unobserved firm heterogeneity that might affect shocks and outcomes.
} 


\begin{tabular}{|c|c|c|c|c|}
\hline \multicolumn{5}{|c|}{ Panel A: Variable Inputs } \\
\hline & (1) & \multicolumn{2}{|c|}{ (2) } & (3) \\
\hline & Hours Worked & \multicolumn{2}{|c|}{ Intermediate Inputs } & Utilized Capital \\
\hline$\triangle \mathrm{TFP}$ & \multirow{2}{*}{$\begin{array}{c}0.05^{* * *} \\
(0.019)\end{array}$} & \multicolumn{2}{|c|}{$0.23^{* * *}$} & 0.02 \\
\hline & & \multicolumn{2}{|c|}{$(0.043)$} & $(0.024)$ \\
\hline$\Delta \xi$ & $0.11^{* * *}$ & \multirow{2}{*}{\multicolumn{2}{|c|}{$\begin{array}{c}0.41^{* * *} \\
(0.011)\end{array}$}} & $0.11^{* * *}$ \\
\hline & $(0.006)$ & & & $(0.008)$ \\
\hline Observations & 6527 & \multicolumn{2}{|c|}{6569} & 6509 \\
\hline$\underline{R^{2}}$ & 0.12 & \multicolumn{2}{|c|}{0.30} & 0.09 \\
\hline \multicolumn{5}{|c|}{ Panel B: Quasi-Fixed Inputs } \\
\hline & (1) & (2) & (3) & (4) \\
\hline & Employment & Hires & Separations & Investment Rate \\
\hline \multirow[t]{2}{*}{$\triangle \mathrm{TFP}$} & $0.08^{* * *}$ & $0.09^{* * *}$ & -0.01 & $0.06^{* *}$ \\
\hline & $(0.013)$ & $(0.017)$ & $(0.017)$ & $(0.002)$ \\
\hline \multirow[t]{2}{*}{$\Delta \xi$} & $0.08^{* * *}$ & $0.07^{* * *}$ & $-0.02^{* * *}$ & $0.04^{* * *}$ \\
\hline & $(0.004)$ & $(0.005)$ & $(0.005)$ & $(0.007)$ \\
\hline Observations & 6517 & 6565 & 6571 & 5334 \\
\hline$R^{2}$ & 0.12 & 0.11 & 0.04 & 0.04 \\
\hline
\end{tabular}

Notes: All dependent variables and the demand and TFP shocks are in delta logs. $\triangle$ TFP is calculated using the Olley and Pakes (1996) control function approach. $\Delta \xi$ is computed using self-reported sectoral price elasticities from the INVIND survey 1996. All specifications include region and industry-year fixed effects. Dependent and independent variables are trimmed to drop outliers above the 99th or below the 1st percentile. Standard errors are calculated from 500 bootstrap simulations. Significance levels: *: $10 \%, * *: 5 \%, * * *: 1 \%$.

number of hours that can be squeezed out of a fixed number of workers, and a firm cannot use more than $100 \%$ of its installed capital. If firms experiencing improvements in productivity or market appeal want to increase their scale, they must act on what we call quasi-fixed inputs of production: the number of workers and installed capital. Panel B of Table 6 considers the extensive margin of inputs adjustment displaying the correlation of growth in the number of workers and the investment rate with changes in TFP and market appeal. One standard deviation increase in market appeal raises investment rate by roughly 1.3 percentage points, a similar increase in $\triangle T F P$ has half that impact. Figures for the elasticity of growth in the (end of the year) labor force are similar. Breaking down the employment growth rate into its determinants, hiring and separation rates, provides additional insights (Columns (2) and (3), Table 6-Panel B). Most of the action takes place on the hiring margin, whereas the elasticity of separations to demand appeal is low and that to TFP is not significant. This can be interpreted as evidence of adjustment costs on the firing margin, consistent with the fact that in the Italian labor market, employment protection legislation imposes firing costs on firms (Schivardi and Torrini, 2008).

The asymmetric (under)response to demand and TFP shocks. Having measured the elasticities of firm growth to demand and TFP shocks, we now revert to our theoretical framework to assess their magnitude. In fact, given an estimate of the demand elasticity and the production function coefficients, the theoretical framework we set up in Section 2 delivers quantitative predictions on the pass-through of demand and supply shocks to inputs and output growth according to the first differenced version of equations (6), (7), and (8). For example, the elasticity of output to TFP shocks is $\frac{\sigma}{\theta}$ and to demand shocks is $\frac{\alpha+\beta+\gamma}{\theta}$. The model abstracts from any potential attenuation effect, such as measurement error or adjustment frictions. Hence, it delivers the theoretical "full" response to changes in productivity and market appeal. We have seen that inputs do not respond to TFP shocks, which is an indication of the dampened response to shocks. 
TABLE 7 Responses to Changes in TFP and Market Appeal: Model's Prediction versus Empirical Estimates

\begin{tabular}{|c|c|c|c|c|c|c|c|c|}
\hline & \multicolumn{2}{|c|}{$\Delta(p+q)$} & \multicolumn{2}{|c|}{$\Delta q$} & \multicolumn{2}{|c|}{$\Delta p$} & \multicolumn{2}{|c|}{$\Delta x$} \\
\hline & Predicted & Actual & Predicted & Actual & Predicted & Actual & Predicted & Actual \\
\hline$\Delta \mathrm{TFP}$ & 2.2 & 0.85 & 2.8 & 1.03 & -0.56 & -0.17 & 2.2 & 0.1 \\
\hline$\Delta \xi$ & 0.56 & 0.37 & 0.44 & 0.24 & 0.11 & 0.13 & 0.56 & 0.21 \\
\hline
\end{tabular}

Notes: $p+q$ indicates nominal output, $q$ is real output deflated with firm-level prices, $x$ represents inputs (labor, capital, and intermediates). The columns labeled Predicted report the elasticity implied by the theoretical model, conditional on the estimates of the parameters of the demand and production functions. The columns labeled Actual display the reducedform estimate of the same elasticity. For these latter, we report the estimate obtained using output for TFP (Table 5, columns (4) and (5)) and revenues for market appeal (Table 5, columns (1) and (2)). For inputs, we use the simple average of the elasticities of variable inputs in Panel A of Table 6.

By comparing the elasticities derived from the model with those estimated in the previous section, we can obtain a precise metric of the degree of such attenuation.

To compute the model predictions, we assume returns to scale of 0.8 and an elasticity of demand of 5 (roughly the cross-sectoral averages from our estimates). The elasticities implied by the model are reported in Table 7. For convenience, we also report the corresponding estimates from Tables 5 and 6 . The differences of the effects estimated under the two approaches is clear. A TFP shock equal to one standard deviation of TFP growth would increase nominal output by $11 \%$, much less than the $29 \%$ implied by the model parameters estimate. For demand, the figures are $12 \%$ and $18 \%$, respectively. These large differences emerge in all the specifications and for all the outcome variables considered. We state this finding explicitly:

Finding 1. The responsiveness of growth measures to productivity and market appeal shocks is substantially lower than that implied by the model.

The comparison of our estimates of the elasticities to demand and productivity shocks with the model predictions delivers a second interesting result. Not only are measured elasticities lower than those that the model predicts, but also the gap is significantly larger for the response to productivity than to market appeal shocks. For example, the predicted elasticity of nominal output to TFP changes is 2.2 , whereas we estimate it to be 0.85 ; our estimate of the elasticity to market appeal is 0.37 , closer to the predicted value of 0.56 . The response of price to shocks is very similar for demand ( 0.11 versus 0.13$)$, although much smaller in absolute value for TFP shocks $(-0.56$ versus -0.17$)$. This evidence can be summarized as follows:

Finding 2. Deviations between actual and predicted pass-through are substantially larger for TFP than for market appeal shocks.

Summing up, we obtain two findings: first, measured elasticities are lower than those implied by the model; second, the attenuation is larger for TFP shocks. Below, we discuss in detail potential explanations for these findings.

Sources of asymmetric and incomplete responses. To understand the findings of the previous section, it is helpful to decompose TFP and market appeal shocks into two components: a transmitted one, defined as the part of the shock inputs respond to, and an untransmitted one, to which inputs are not responsive. Namely, we have:

$$
\begin{aligned}
\Delta T F P_{i t} & =\Delta \omega_{i t}+\Delta \eta_{i t} \\
\Delta \xi_{i t} & =\Delta \xi^{*}+\Delta \zeta_{i t} .
\end{aligned}
$$


This decomposition is routinely performed for TFP, and the Olley and Pakes (1996) procedure offers a way to separately identify the two components. By definition of control function, which proxies the unobserved productivity shock with a function of investments, $\Delta \omega$ captures the transmitted TFP component whereas $\Delta \eta$, being orthogonal to inputs, is the untransmitted component. The usual interpretation maintains that the transmitted component is the "true" productivity shock, which is observed and taken into consideration when formulating demand for inputs. The $\Delta \eta$ shock is instead seen as measurement error or as transitory shocks occurring after input choices have been made (De Loecker and Warzynski, 2012). Although market appeal shocks have not been analyzed in this fashion by prior literature, one can extend this definitional decomposition by labeling $\Delta \xi^{*}$ as the transmitted component and $\Delta \zeta$ as the untransmitted one. Unlike the TFP case, the identification procedure of market appeal shocks cannot disentangle the two.

We derived our model by assuming away any untransmitted component. It is immediate to extend the derivation of equilibrium quantities to this generalization. Equations (6) and (7) become:

$$
\begin{aligned}
& \Delta q=c_{q}+\frac{\sigma}{\theta} \Delta \omega+\Delta \eta+\frac{\alpha+\beta+\gamma}{\theta} \Delta \xi^{*} \\
& \Delta p=c_{p}-\frac{1}{\theta} \Delta \omega-\frac{1}{\sigma} \Delta \eta+\frac{1-\alpha-\beta-\gamma}{\theta} \Delta \xi^{*}+\frac{1}{\sigma} \Delta \zeta .
\end{aligned}
$$

This formalization makes it apparent how the presence of an untransmitted component links to our attenuation result. Assuming that the two components are uncorrelated, a regression of growth on $\triangle T F P$ and $\triangle \xi$ will deliver a weighted average of the coefficients on the transmitted and untransmitted components for each shock. In the quantity equation, the coefficient on TFP will be between $\frac{\sigma}{\theta}$ and one, attenuated with respect to the response in the $\Delta \omega$ component alone. The coefficient on $\Delta \xi$ will lie between $\frac{\alpha+\beta+\gamma}{\theta}$ and zero. Once again, this leads to a lower elasticity than that implied by the transmitted component. For the price equation, note that $\frac{1}{\theta}>\frac{1}{\sigma}$, so that attenuation will result (in absolute value) for TFP shocks, whereas $\frac{1-\alpha-\beta-\gamma}{\theta}<\frac{1}{\sigma}$, so that the coefficient on the total market appeal shock will be larger than the elasticity to the transmitted component. These are exactly the patterns we obtained in Table 7. To further corroborate our interpretation, in Table A-7 of the web Appendix, we report the results of the growth regressions when using the predicted value of the control function as measure of $\Delta \omega$. We find that the coefficients increase substantially in absolute value, in line with the idea that, when focusing on the transmitted component, the elasticity is larger. ${ }^{15}$ The question we turn to now is what the untransmitted component represents.

Measurement error. In the standard productivity literature, our findings would be read as indicative that productivity and demand shocks are measured with error (which provides for the incomplete response) and that this is more prominent for productivity (delivering the asymmetry). Our procedure derives demand and TFP shocks as residuals of an estimated equation, and then uses such shocks as explanatory variables for input, prices and output themselves. Measurement error in variables would pollute our measures of the shocks and imply that the regressors we use in equation (17) are error-ridden, potentially explaining why the coefficients are attenuated. The role of measurement error could be particularly relevant in our setting as we perform our estimation in first differences, which might exacerbate this problem. Although measurement error does not necessarily delivers a downward bias in a nonlinear context and when multiple variables are measured with error, it admittedly represents a viable potential explanation for our results.

${ }^{15}$ The size of the responses is still below that predicted by the frictionless model. This suggests that, even conditionally on responding to the shock, firms might face adjustment costs that prevent full adjustment, and/or that $\Delta \omega$ might be measured with error. 
To thoroughly assess the influence of measurement error on our estimates of the passthrough of shocks, we perform a Monte Carlo study. We generate productivity and demand shocks according to an $\mathrm{AR}(1)$ process with persistence and volatility matching that of our estimated time series for $\triangle T F P$ and $\triangle \xi$, and we obtain time series for growth of quantities, prices, and inputs using (6), (7), and (8) and our parameter estimates for the demand and the production function. By construction, the "true" elasticity of these growth measures to demand and TFP shock is that implied by our model. Next, we introduce measurement error in revenues, prices, and input measures adding to each of them an i.i.d. zero-mean normal disturbance whose variance is set to be a fraction of the variance of the variable measured without error. We then follow our procedure, using these error-ridden variables to obtain measurement error-tainted estimates of demand and TFP shocks. Finally, we repeat the regressions in (17) using the error-ridden variables and shocks.

A detailed discussion of the Monte Carlo study and its results is provided in Section B.4 of the web Appendix; here, we summarize the main conclusions. The exercise does show that measurement error can result in sizeable attenuation of the measured pass-through; therefore, we should exercise caution when making quantitative statements on the size of this dampening effect. However, even if we allow measurement error to be large and pervasive, we find it hard to replicate our findings. For instance, to reach the same degree of attenuation in the response of quantity to TFP shocks, we need to allow for measurement error to be responsible for nearly half of the variation in revenues, prices, and each of the three inputs of production: this seems a rather extreme scenario. Even more important, measurement error tends to distort the estimate of the elasticity of growth measures to demand shocks more than that to productivity shocks. This implies that a measurement error story would have us find the opposite of what we actually document in terms of asymmetric effect: the response to demand should be more attenuated than the response to TFP shocks. Similar conclusions are reached when we also introduce measurement error in the production function coefficients (see Section B.4 of the web Appendix for details). In short, although the role of measurement error should be taken into consideration when interpreting our results quantitatively, it cannot fully account for our main findings.

Adjustment frictions. By completely ascribing the untransmitted components behavior to classical measurement error, we are unable to reproduce the pass-through of shocks to growth we observe in the data. Therefore, we propose another interpretation for the nature of $\Delta \eta$ and $\Delta \zeta$ which ties in to the large literature that has pointed to the presence of frictions limiting firms' ability to adjust to shocks. ${ }^{16}$ We explore the possibility that firms do not react fully to shocks because they are impaired to do so by the presence of frictions. In this interpretation, $\Delta \eta$ and $\Delta \zeta$ would be the component of the productivity and demand shocks to which the firm is unable to respond.

Positing that the lack of response is due to frictions implies a deviation from the timing assumed when we think of it as measurement error. In the latter case, firms do not act on the untransmitted component because this is realized after input choices are made, or because the measured shock is actually a consequence of measurement error. In the former, the entire shock ( $\triangle T F P$ or $\triangle \xi$ ) is observed by the firm but the existence of frictions only allows to respond to part of it $\left(\Delta \omega\right.$ and $\left.\Delta \xi^{*}\right)$. Note that, technically, this distinction has no consequences in terms of the estimation of the shocks: it is just a different interpretation of the untransmitted component. Furthermore, the two interpretations are not mutually exclusive. Although we will present evidence consistent with the magnitude of $\Delta \eta$ and $\Delta \zeta$ being driven by something else than measurement error, we acknowledge that measurement error can also influence the degree

${ }^{16}$ Recent contributions include studies of investment adjustment costs (Asker, Collard-Wexler, and De Loecker, 2014), financial constraints (Banerjee and Moll, 2012; Midrigan and $\mathrm{Xu}, 2014$ ), and employment protection legislation (Petrin and Sivadasan, 2013). Hamermesh and Pfann (1996) provides a comprehensive survey of the earlier literature. 
TABLE 8 Price Elasticity and Firm Size

\begin{tabular}{lcccc}
\hline & Employment & Market Share & $\log ($ Employment $)$ & $\log ($ Market Share) \\
\hline Elasticity of & 0.22 & 0.00 & $0.002^{* *}$ & 0.001 \\
demand $(\sigma)$ & $(0.81)$ & $(0.00)$ & $(0.001)$ & $(0.001)$ \\
$N$ & 1927 & 1927 & 1927 & 1927 \\
\hline
\end{tabular}

Notes: The table reports the correlation between measures of firm size and the price elasticity faced by the firm. Employment is computed as the number of employees and market share as the fraction of revenues (in euros) the firm accounts for in its sector. The price elasticity of demand is self-reported by firm in response to the question described in Section 4. The sample consists only of observations collected in years 1996 and 2007, as those are the two waves in which the question on price elasticity is included in the INVIND survey. Significance level: ${ }^{* *}: 5 \%$.

of shock pass-through we detect. We want to stress, though, that these interpretations have quite different implications. If the lack of response is due only to measurement issues or to unforeseen shocks, there is nothing firms can do about it. If the size of the untransmitted components also depends on frictions, instead, understanding what these hurdles are can help firms to reduce such obstacles to growth.

To explain our results, we need to posit the existence of a specific class of frictions whose strength depends on the nature of the shock. In the next section, we introduce a specific type of friction that induces asymmetric adjustments in response to productivity and demand shocks and provide some direct evidence of their relevance in explaining our findings. Finally, because we have estimated the production function abstracting from the presence of frictions, with the exception of the one period lag in building capital, one may be concerned that this extension invalidates our inference on the productivity shocks. In Section B.5 of the web Appendix we extensively discuss this issue, showing the robustness of our approach to the introduction of a broad class of adjustment costs.

Variable markups. Our model assumes a CES demand and, therefore, it implies that firms set a constant markup. Variable markups models feature incomplete pass-through of cost shocks into prices and output, which could explain the low responsiveness to cost shocks. Furthermore, if our functional form assumptions for the demand were unwarranted, we would have yet another source of error in the measurement of the shock.

In Section 3, we presented the sectors included in our sample, providing statistics on their structure and competitive environment broadly consistent with the assumption of monopolistic competition. In Table 8, we exploit the information on self-reported demand elasticities contained in the INVIND survey to offer one additional piece of evidence in support to that assumption. We present the correlation between self-reported price elasticity of demand and firm size, measured either as market share at the subsector level or as number of employees. In both cases, the correlation is low and hardly ever significant, consistently with what we would expect in a monopolistic competition setting.

\section{Managerial ability as a firm-specific adjustment friction}

The most commonly cited obstacles to firm growth, such as the need to pay bribes (Hsieh and Klenow, 2009) or firing costs (Hopenhayn and Rogerson, 1993), have the same impact whether a firm wanted to grow because it became more productive or because of an increase in its market appeal. Hence, they cannot give rise to the asymmetry we documented. This could instead be rationalized if shocks had different degrees of persistence (Asker, Collard-Wexler, and De Loecker, 2014). However, in Panel C of Table 4, we showed that the persistence of productivity shocks is larger, although also imprecisely estimated, than that of demand shocks. Hence, the properties of the processes underlying the shocks would have us finding asymmetry of the sign 
opposite to that we detect in our results. This leaves the existence of frictions that bite differently in response to productivity and demand shocks as a viable explanation to our main findings.

We propose here a concrete example of one such friction, that is, the ability of management to implement change within the organization. The discussion in this section has the goal of fixing ideas on the class of mechanisms that could account for the asymmetric response we documented. Although the narrative we propose is not the only story consistent with such findings, ${ }^{17}$ and it hinges on strong assumptions, it has the benefit that we can exploit several measures of managerial quality to provide some suggestive evidence in its support.

We start by positing that changing the inputs level following demand and productivity shocks may require the firm to undertake some reorganization activity. Reorganizations are costly activities and can constitute a barrier to factors adjustment. For simplicity, we assume that reorganization can be triggered by shocks but does not raise productivity or market appeal itself. Under this type of friction, an asymmetric response to shocks would result if TFP shocks are more likely to require reorganization than demand shocks. The idea behind this postulate is that TFP shocks represent a shift in the production technology, and responding to them likely entails shifting the way things are done within the firm: for instance, a change in the skill mix of the employees or the use of different types of capital inputs. If the firm's management lacks the expertise to implement these complementary reorganizations, the adjustment of the scale of operation following a TFP shock will be incomplete. This scenario might be less likely for demand shocks, where the need to cater to a larger mass of customers can be met by simply scaling up production without necessarily requiring reorganization.

The framework sketched in Section 5 delivers an empirical prediction for the presence of a managerial ability friction: the size of the untransmitted component of TFP should be smaller for firms with better managerial ability, as they are more likely to be able to reorganize their activities to take full advantage of the productivity shock. ${ }^{18}$ Under our stated assumption, instead, managerial ability should not impact the incompleteness of the pass-through of demand shocks. Given a measure of firms' capacity to restructure after shocks, we can test this prediction by allowing the pass-through of the shocks to differ according to the firm categorization. We implement this idea running the following regression:

$$
\Delta y_{i t}=b_{0}+b_{1} \Delta T F P_{i t}+b_{2} D_{R} \Delta T F P_{i t}+b_{3} \Delta \xi_{i t}+b_{4} D_{R} \Delta \xi_{i t}+b_{5} D_{R}+b_{6} X_{i t}+e_{i t},
$$

where $D_{R}$ is an indicator that takes value 1 if the firm is characterized by high restructuring costs. We construct four proxies for firms' ability to restructure and check whether firms that score low in this metric are also less responsive to TFP shocks but not to demand shocks:

- Self-reported measure of reorganization constraints from the INVIND survey. Firms that do not meet the investment goal stated in the past year's interview are asked to provide a reason for that: around $55 \%$ of firms points to problems with the internal reorganization of the firm. We assume that firms selecting this option are facing higher costs of organizational restructuring.

- Identity of the controlling shareholder. A recent literature has documented a large degree of heterogeneity in firms' managerial practices and organizational structures and linked their quality to the ownership structure. In particular, we identify family or government-controlled firms (around half of the sample) as less efficiently managed than widely-held or institutionally controlled firms because they are more inclined to appoint their management based on reasons other than competence (Bloom and Van Reenen, 2007; Bloom, Sadun, and Van Reenen, 2012; Lippi and Schivardi, 2014).

\footnotetext{
${ }^{17}$ For example, credit constraints could have different effects depending on the nature of the shock if we assume that market appeal shocks are easier to collateralize than productivity ones.

${ }^{18}$ Once we introduce heterogeneity in firms' ability to respond to TFP shocks, the standard Olley and Pakes (1996) assumption that firms have the same control function is violated. In Section B.5 of the web Appendix, we assess the quantitative consequences of ignoring differences in the control functions on the estimation of the production function coefficients.
} 
TABLE 9 Evidence of Organizational Hurdles

\begin{tabular}{|c|c|c|c|c|c|c|c|c|}
\hline \multirow[t]{2}{*}{ Hurdle: } & \multicolumn{2}{|c|}{ Self-Reported } & \multicolumn{2}{|c|}{ Family Firms } & \multicolumn{2}{|c|}{$\begin{array}{c}\text { Low-Manager } \\
\text { Quality }\end{array}$} & \multicolumn{2}{|c|}{$\begin{array}{c}\text { Low-Workforce } \\
\text { Quality }\end{array}$} \\
\hline & $\begin{array}{c}\text { (1) } \\
\text { Output }\end{array}$ & $\begin{array}{c}(2) \\
\text { Price }\end{array}$ & $\begin{array}{c}\text { (3) } \\
\text { Output }\end{array}$ & $\begin{array}{c}(4) \\
\text { Price }\end{array}$ & $\begin{array}{c}\text { (5) } \\
\text { Output }\end{array}$ & $\begin{array}{c}(6) \\
\text { Price }\end{array}$ & $\begin{array}{c}\text { (7) } \\
\text { Output }\end{array}$ & $\begin{array}{c}(8) \\
\text { Price }\end{array}$ \\
\hline$\triangle \mathrm{TFP}$ & $\begin{array}{l}1.09^{* * *} \\
(0.041)\end{array}$ & $\begin{array}{r}-0.18^{* * *} \\
(0.009)\end{array}$ & $\begin{array}{l}1.11^{* * *} \\
(0.038)\end{array}$ & $\begin{array}{c}-0.18^{* * *} \\
(0.07)\end{array}$ & $\begin{array}{l}1.17^{* * *} \\
(0.055)\end{array}$ & $\begin{array}{c}-0.20^{* * *} \\
(0.012)\end{array}$ & $\begin{array}{l}1.13^{* * *} \\
(0.043)\end{array}$ & $\begin{array}{r}-0.17^{* * *} \\
(0.007)\end{array}$ \\
\hline$\Delta \mathrm{TFP} \times$ Hurdle & $\begin{array}{c}-0.14^{* *} \\
(0.056)\end{array}$ & $\begin{array}{c}0.02^{*} \\
(0.012)\end{array}$ & $\begin{array}{c}-0.16^{* * *} \\
(0.051)\end{array}$ & $\begin{array}{c}0.30^{* * *} \\
(0.009)\end{array}$ & $\begin{array}{r}-0.17^{* *} \\
(0.085)\end{array}$ & $\begin{array}{c}0.04^{* *} \\
(0.018)\end{array}$ & $\begin{array}{c}-0.17^{* * *} \\
(0.065)\end{array}$ & $\begin{array}{c}0.02^{*} \\
(0.013)\end{array}$ \\
\hline$\Delta \xi$ & $\begin{array}{c}0.25^{* * *} \\
(0.011)\end{array}$ & $\begin{array}{c}0.13^{* * *} \\
(0.003)\end{array}$ & $\begin{array}{c}0.24^{* * *} \\
(0.010)\end{array}$ & $\begin{array}{c}0.13^{* * *} \\
(0.002)\end{array}$ & $\begin{array}{c}0.25^{* * *} \\
(0.016)\end{array}$ & $\begin{array}{c}0.14^{* * *} \\
(0.004)\end{array}$ & $\begin{array}{c}0.24^{* * *} \\
(0.013)\end{array}$ & $\begin{array}{c}0.13^{* * *} \\
(0.003)\end{array}$ \\
\hline$\Delta \xi \times$ Hurdle & $\begin{array}{l}-0.00 \\
(0.015)\end{array}$ & $\begin{array}{c}-0.00 \\
(0.004)\end{array}$ & $\begin{array}{c}-0.01 \\
(0.015)\end{array}$ & $\begin{array}{c}-0.00 \\
(0.004)\end{array}$ & $\begin{array}{c}-0.03 \\
(0.023)\end{array}$ & $\begin{array}{c}0.00 \\
(0.006)\end{array}$ & $\begin{array}{c}0.01 \\
(0.019)\end{array}$ & $\begin{array}{l}0.00 \\
(0.004)\end{array}$ \\
\hline Hurdle & $\begin{array}{c}0.01^{* *} \\
(0.003)\end{array}$ & $\begin{array}{l}-0.00 \\
(0.001)\end{array}$ & $\begin{array}{r}-0.01^{* *} \\
(0.003)\end{array}$ & $\begin{array}{c}0.00^{* * *} \\
(0.001)\end{array}$ & $\begin{array}{l}-0.00 \\
(0.005)\end{array}$ & $\begin{array}{c}0.00 \\
(0.001)\end{array}$ & $\begin{array}{c}-0.00 \\
(0.003)\end{array}$ & $\begin{array}{l}0.00 \\
(0.001)\end{array}$ \\
\hline Observations & 4970 & 5000 & 6219 & 6258 & 2050 & 2065 & 3647 & 3669 \\
\hline$R^{2}$ & 0.52 & 0.76 & 0.53 & 0.76 & 0.54 & 0.81 & 0.52 & 0.74 \\
\hline
\end{tabular}

Notes: All dependent variables as well as the demand and TFP shocks are in delta logs. $\triangle$ TFP is calculated using the Olley and Pakes (1996) control function approach. $\Delta \xi$ is computed using self-reported sectoral price elasticities from the INVIND survey 1996. Self-reported is an indicator variable for firms that face higher costs in reshaping their internal organization. It takes value 1 for firms reporting in the INVIND survey that they have not met their investment plans for the past year due to "problems with the internal organization of the firm." Family firms is an indicator variable for firms that are controlled by an individual/family or by the government. Low-manager quality is an indicator variable for firms whose manager fixed effects is below the median. Low-workforce quality is an indicator variable for firms whose share of college graduates in the workforce is below the median. Output is deflated using firm-level prices. Employment is measured as the number of workers employed at the firm at the end of the year. All specifications include region and industry-year fixed effects. Both dependent and independent variables are trimmed to drop outliers above the 99th or below the 1st percentile. Standard errors are calculated from 500 bootstrap simulations. Significance levels: *: 10\%, $* *$ : $5 \%, * * *: 1 \%$

- Manager fixed effects. For the period up to 1997, we have access to the individual records of all the employees of the firms. We compute the individual fixed effects in the wage equation following Abowd, Kramarz, and Margolis (1999) (see Macis and Schivardi, forthcoming, for details); this fixed effect is interpreted in the literature as a measure of ability. For each firm, we compute the average effect of the executives and use this as a measure of managerial ability. Given that we have only data up to 1997 , our sample shrinks considerably. To increase statistical power, we exploit the fact that executive turnover is low (the probability that an executive leaves a firm is around $10 \%$ per year) and impute the last (first) value of executive quality forward (backward) for four years.

- Human capital of the workforce. We take the share of college graduates working for each firm, which we observe in 2000 and in 2006, as a characteristic associated to the capacity of a firm to restructure (Caroli and Van Reenen, 2001; Bresnahan, Brynjolfsson, and Hitt, 2002). We create an indicator equal to one if a firm is below the median of college graduates at the sectoral level. We use the 2000 dummies for the years 1995-2002 and the 2006 dummy for the following years.

All those measures have potential shortcomings and, in some cases, their implementation forces us to work with significantly smaller samples. These limitations notwithstanding, the pattern emerging from the results, reported in Table 9, is striking. All the distinct proxies of a firm's ability to handle reorganization show a significant relationship with the degree of response to TFP: organizationally impaired firms adjust both output and prices less than the other firms following TFP shocks. Instead, no difference emerges in the strength of the response to market appeal shocks. 


\section{Conclusions}

In this article, we use a unique data set on a panel of Italian manufacturing firms which contains information on firm-level prices. We identify and distinguish the role of idiosyncratic productivity and demand in firm growth and proceed to show that, though mostly neglected in the literature, heterogeneity in demand is an important determinant of growth. We also document that the measured effect of the shocks is lower than that a frictionless theoretical framework would predict. We argue that these results cannot be entirely explained by the presence of measurement error, and link it to the presence of adjustment costs to shocks. To support this claim, we show that the incompleteness of the pass-through of shocks is different for technology and demand shocks and provide suggestive evidence that it links to the ability of the firm to undertake organizational changes.

In terms of future research, it will be interesting to study within-firm frictions to growth. Our evidence suggests that barriers to the efficient allocation of resources are not exclusively of a regulatory nature, as the literature on this subject has typically assumed (Hopenhayn and Rogerson, 1993; Restuccia and Rogerson, 2008; Hsieh and Klenow, 2009). This conclusion has important implications for the debate on how to reduce productivity losses from misallocation. On the one hand, regulation and corruption call directly into question government policies. On the other hand, the type of firm idiosyncratic friction we stress are much less under the direct policy influence. Recent literature has shown that they depend on a plurality of factors, such as corporate governance and control, managerial and entrepreneurial abilities, work attitudes, competition in the product markets (Bloom and Van Reenen, 2010). Our results imply that managerial practices are not only important for within-firm productivity growth, but also for the process of efficient factors allocation across firms. Improving our understanding of the determinants of firms' reaction to shocks of different nature may contribute in an innovative way to the debate on the efficient allocation of resources.

\section{References}

Abowd, J.M., Kramarz, F., And Margolis, D.N. "High Wage Workers and High Wage Firms.” Econometrica, Vol. 67 (1999), pp. 251-333.

Ackerberg, D., Benkard, L., Berry, S., And Pakes, A. "Econometric Tools for Analyzing Market Outcomes.” In J. Heckman and E. Leamer, eds., Handbook of Econometrics, Volume 6, pp. 4171-4276. Amsterdam: North Holland, 2007.

Asker, J., Collard-Wexler, A., And De Loecker, J. “Dynamic Inputs and (Mis)Allocation.” Journal of Political Economy, Vol. 122 (2014), pp. 1013-1063.

BanerJee, A. And Moll, B. “Why Does Misallocation Persist?” American Economic Journal: Macroeconomics, Vol. 2 (2012), pp. 189-206.

Bartelsman, E., Haltiwanger, J., And Scarpetta, S. “Cross-Country Differences in Productivity: The Role of Allocation and Selection." American Economic Review, Vol. 103 (2013), pp. 305-334.

BERRY, S. "Estimating Discrete-Choice Models of Product Differentiation.” RAND Journal of Economics, Vol. 25 (1994), pp. 242-262.

Bloom, N., Sadun, R., And Van Reenen, J. "Recent Advances in the Empirics of Organizational Economics." Annual Review of Economics, Vol. 2 (2010), pp. 105-137.

. "Americans Do I.T. Better: US Multinationals and the Productivity Miracle." American Economic Review, Vol. 102 (2012), pp. 167-201.

Bloom, N. and Van Reenen, J. "Measuring and Explaining Management Practices Across Firms and Countries." The Quarterly Journal of Economics, Vol. 122 (2007), pp. 1351-1408.

_ . "Human Resource Management and Productivity." In O. Ashenfelter and D. Card, eds., Handbook of Labor Economics, Volume 4. Amsterdam, The Netherlands: Elsevier, 2010.

Brandolini, A. And Cipollone, P. "Multifactor Productivity and Labour Quality in Italy, 1981-2000." Temi di discussione, Bank of Italy, 2001.

Bresnahan, T., Brynjolfsson, E., And Hitt, L. "Information Technology, Workplace Organization, and the Demand for Skilled Labor: Firm-Level Evidence.” Quarterly Journal of Economics, Vol. 117 (2002), pp. 339-376.

Carlsson, M., Messina, J., And SKans, N.O.O. “Firm-Level Shocks and Labor Adjustments.” Mimeo, Uppsala University, 2014. 
Caroli, E. and Van Reenen, J. "Skill-Biased Organizational Change? Evidence from a Panel of British and French Establishments.” Quarterly Journal of Economics, Vol. 116 (2001), pp. 1449-1492.

De Loecker, J. "Product Differentiation, Multi-Product Firms and Estimating the Impact of Trade Liberalization on Productivity." Econometrica, Vol. 79 (2011), pp. 1407-1451.

De Loecker, J., Goldberg, P., Khandelwal, A., and Pavcnik, N. "Prices, Markups and Trade Reform.” Econometrica, Vol. 84 (2016), pp. 445-510.

De Loecker, J. And Warzynski, F. “Markups and Firm-Level Export Status.” The American Economic Review, Vol. 102 (2012), pp. 2437-2471.

Dranove, D., Forman, C., Goldfarb, A., And Greenstein, S. "The Trillion Dollar Conundrum: Complementarities and Health Information Technology.” American Economic Journal: Economic Policy, Vol. 6 (2014), pp. 239-270.

Dunne, T., Roberts, M., And Samuelson, L. "Patterns of Entry and Exit in US Manufacturing." RAND Journal of Economics, Vol. 19 (1988), pp. 495-515.

—. "The Growth and Failure of US Manufacturing Plants." Quarterly Journal of Economics, Vol. 104 (1989), pp. 671-698.

Evans, D. “The Relationship between Firm Growth, Size, and Age: Estimates for 100 Manufacturing Industries.” Journal of Industrial Economics, Vol. 35 (1987a), pp. 567-581.

. "Testing Alternative Theories of Firm Growth.” Journal of Political Economy, Vol. 95 (1987b), pp. 657-674.

Fan, X., Roberts, M., Xu, D.Y., And Zhang, S. “A Structural Model of Demand, Cost, and Export Market Selection for Chinese Footwear Producers.” NBER Working Paper no. 17725, 2012.

Foster, L., Haltiwanger, J., And Syverson, C. "Reallocation, Firm Turnover, and Efficiency: Selection on Productivity or Profitability?” American Economic Review, Vol. 98 (2008), pp. 394-425.

."The Slow Growth of New Plants: Learning About Demand?” Economica, Vol. 83 (2016), pp. 91-129.

Gandhi, A., Navarro, S., And Rivers, D. "On the Identification of Production Functions: How Heterogeneous Is Productivity?” Mimeo, University of Wisconsin-Madison, 2013.

Gourio, F. And Rudanko, L. “Customer Capital.” Review of Economic Studies, vol. 81 (2014), pp. 1102-1136.

Hamermesh, D. And Pfann, G. “Adjustment Costs in Factor Demand.” Journal of Economic Literature, Vol. 34 (1996), pp. 1264-1292.

Hopenhayn, H. "Entry, Exit, and Firm Dynamics in Long Run Equilibrium.” Econometrica, Vol. 60 (1992), pp. 11271150 .

Hopenhayn, H. And Rogerson, R. “Job Turnover and Policy Evaluation: A General Equilibrium Analysis.” Journal of Political Economy, Vol. 101 (1993), pp. 915-938.

Hsien, C. And Klenow, P. "Misallocation and Manufacturing TFP in China and India." The Quarterly Journal of Economics, Vol. 124 (2009), p. 1403.

Jovanovic, B. "Selection and the Evolution of Industry." Econometrica, Vol. 50 (1982), pp. 649-670.

Klette, T. AND GRILICHES, Z. "The Inconsistency of Common Scale Estimators When Output Prices are Unobserved and Endogenous.” Journal of Applied Econometrics, Vol. 11 (1996), pp. 343-361.

LipPI, F. AND Schivard, F. “Corporate Control and Executive Selection." Quantitative Economics, Vol. 5 (2014), pp. 417-456.

Macis, M. AND SChIVARDI, F. "Exports and Wages: Rent Sharing, Workforce Composition or Returns to Skills?” Journal of Labor Economics, (forthcoming).

Melitz, M. "Estimating Firm-Level Productivity in Differentiated Product Industries." Mimeo, Harvard University, 2000.

Midrigan, V. And Xu, D. "Finance and Misallocation: Evidence from Plant-Level Data." American Economic Review, Vol. 104 (2014), pp. 422-458.

Olley, S. ANd PAKes, A. “The Dynamics of Productivity in the Telecommunications Equipment Industry." Econometrica, Vol. 64 (1996), pp. 1263-1298.

Petrin, A. And Sivadasan, J. "Estimating Lost Output from Allocative Inefficiency, with an Application to Chile and Firing Costs." Review of Economics and Statistics, Vol. 95 (2013), pp. 286-301.

Restuccia, D. And Rogerson, R. "Policy Distortions and Aggregate Productivity with Heterogeneous Establishments." Review of Economic Dynamics, Vol. 11 (2008), pp. 707-720.

Schivardi, F. AND Torrini, R. "Identifying the Effects of Firing Restrictions through Size-Contingent Differences in Regulation.” Labour Economics, Vol. 15 (2008), pp. 482-511.

Syverson, C. "What Determines Productivity?” Journal of Economic Literature, Vol. 49 (2011), pp. 326-365.

TrajtenBerg, M. "The Welfare Analysis of Product Innovation with an Application to Computer Tomography Scanners." Journal of Political Economy, Vol. 97 (1989), pp. 444-479.

\section{Supporting information}

Additional supporting information may be found in the online version of this article at the publisher's website:

\section{Online Appendix}

